\title{
Implementasi Sifat Ta'awun Dalam Lembaga Keuangan Syariah Melalui Akad Al-Qardh
}

\author{
Rukiah \\ Dosen Fakultas Ekonomi dan Bisnis Islam IAIN Padangsidimpuan. \\ Emai: rukiahlubis@gmail.com
}

\begin{abstract}
Abstrak
Tujuan dari penulisan artikel ini adalah untuk mengetahui konsep Al-qardh dalam lembaga keuangan syariah dari tinjauan fiqh, bagaimana kendala kendala pelaksanaan di lapangan, serta produk- produk apa saja yang memakai akad ini di lembaga keuangan. Metode analisis yang dipakai adalah kajian literatur dan temuan di lapangan. Hasil yang ditemukan adalah bahwa, akad qardh dalam prakteknya, belum maksimal dimanfaatkan lembaga keuangan untuk optimalisasi fungsi sosialnya, dan kurangnya kesadaran nasabah untuk mengembalikan hutang qardh, sebab adanya persepsi nasabah bahwa hutang qardh itu adalah dana kebajikan.
\end{abstract}

\section{Abstrak}

The purpose this paper were to find out the concept of Al-qardh in Islamic financial institutions from a review of fiqh, what are the obstacles of implementation in the field, and what products use this contract in financial institutions. The analytical method used is a literature review and findings in the field. The results found were qardh contract in practice, it was not maximally utilized by financial institutions to optimize their social functions, and the lack of awareness of customers to return qardh debt, because there was a customer's perception that the qardh debt was a virtue fund.

Kata kunci: Implementasi, Sifat Ta'awun, Lembaga Keuangan Syariah, . 


\section{Pendahuluan}

Islam sangat menganjurkan pemeratan pendapatan dan hak kepemilikan terhadap harta, oleh karena itu dalam memperoleh harta dan memenuhi kebutuhan akan hidup, tentu manusia memiliki kemampuan yang berbeda- beda, hal ini bisa sebabkan sumber daya yang terbatas yang dimiliki setiap individu misalnya adanya ketidakseimbangan dalam kepemilikan dana, keahlian, fasilitas, akses terhadap informasi dan lain-lain, dengan adanya kondisi ini tentu akan terjadi kesenjangan ekonomi.

Lembaga keuangan sebagai lembaga intermediasi, sangat berperan besar dalam mengatasi kesenjangan kepemilikan terhadap akses sumber daya finansial. Lembaga keuangan adalah lembaga yang dibentuk untuk mengimpun dan menyalurkan dana kepada masyarakat agar perkonomian berjalan. Perbankan syariah sebagai salah satu pilar penggerak perekonomiian dikenal memiliki pondasi yang kuat, karena produk/ akad- akadnya berbasis kepada penggerak sector riil, penopang UKM. Kemudian perbankan syariah adalahSalah satu lembaga yang berperan untuk memberi fasilitas pinjaman non komersil melalui akad pembiayaan Qardul Hasan.

Sejak berdirinya bank syariah di awal tahun 1990-an, perekonomian Indonesia seolah mendapatkan angin segar ditengah krisis ekonomi yang melanda di masa itu. Dimana Bank Syariah bisa bertahan ditengah krisis. Sampai saat ini perkembangan jumlah bank syariah dan asset mengalami peningkatan yang menggembirakan dimana hingga tahun 2018 jumlah institusi Bank Syariah baik BUS, UUS dan BPRS sudah mencapai 202 unit dengan market share 5,70 persen serta Asset Rp. 444.43 trilliun 1. Begitu cepat perkembangan industri

${ }^{1}$ Otoritas Jasa keuangan (OJK), 2018, Perbankan Syariah (Snapsot)https://www.ojk.go.id/id/kanal/syariah/berita-dankegiatan/publikasi/Pages/SnapshotPerbankan-Syariah-Indonesia-Juni-2018.aspx, diakses tgl 9 Mei 2019

88 Studi Multidisipliner Volume 6 Edisi 12019 M/ $1440 \mathrm{H}$ 
keuangan syariah dalam peningkatan asset, akan tetapi dari segi pembiayaan (Qardh-ul Hasan) 2khususnya yang berorientasi pada sosial dan kebajikan (Tabarru / non komersil) terlihat masih minim yaitu sekitar 2,23 persendari keseluruhan pembiayaaan yang disalurkan bank syariah kepada masyarakat ${ }^{3}$.

Sistem pinjamn non komersil ini hanya ada di lembaga keuangan syariah, dan menjadi salah satu ciri khas yang membedakannya dengan perbankan konvensional. Secara spesifik dinamakan soft and benevolent loan. Pinjaman ini dikhususkan untuk masyarakat yang benar-benar sangat membutuhkan dan tidak memakai intrumen margin ataupun bagi hasil, dalam hal ini memiliki makna tolong menolong (Ta'awun) sesuai dengan firman Allah dalam QS : Al- Maidah : $5(2)$

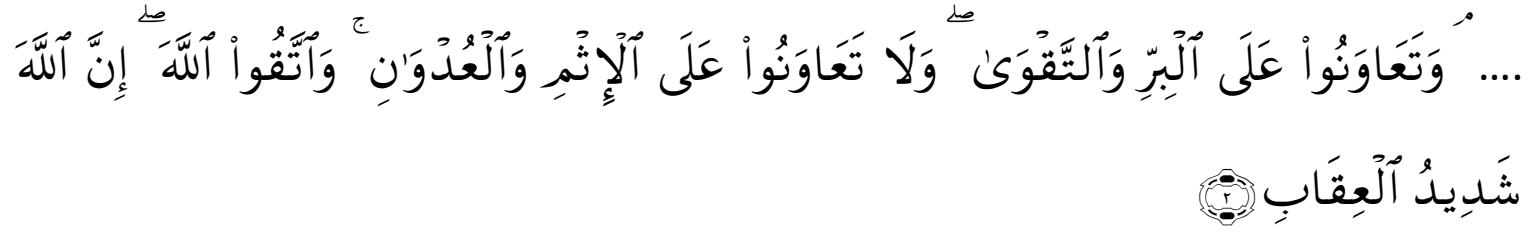

Artinya: Dan tolong-menolonglah kamu dalam (mengerjakan) kebajikan dan takwa, dan jangan tolong-menolong dalam berbuat dosa dan pelanggaran. dan bertakwalah kamu kepada Allah, Sesungguhnya Allah Amat berat siksa-Nya. ${ }^{4}$

Konsep tolong menolong dalam ayat ini sudah jelas, mengisyaratkan bahwa segala kegiatan yang intinya untuk beribadah dan mencari penghidupan didunia, manusia dianjurkan agar saling tolong menolong. Sangat disayangkan sampai saat ini industri perbankan Syariah Nasional sepertinya belum memaksimalkan transaksi dalam akadqardh ini. Sementara fungsi utama perbankan syariah

2Ada suatu jenis Qardh yang disebut Qardh-ul Hassan yaitu kontrakQardh yang khususnya untuk tujuan sosial, Qardhul Hassan adalah suatu interest free financig

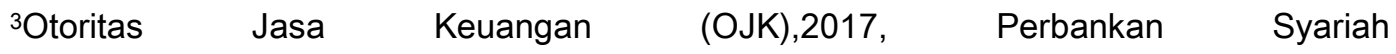
(Snapsot)https://www.ojk.go.id/id/kanal/syariah/berita-dankegiatan/publikasi/Pages/SnapshotPerbankan-Syariah-Indonesia-Juni-2018.aspx, diakses tgl 4 Mei 2019

${ }^{4} \mathrm{Al}$ - Quran dan terjemahan Al -bayan...................hlm. 155 
didirikan adalah untuk membantu pemerintah dalam menunjang pembangunan nasional sebagai mana yang tertuang dalam Undang- undang Nomor 21 tahun $2008^{5}$ tentang perbankan syariah.

Adapun kaitannya dengan akad qard, yang dalam kehidupan sehari - hari tentu kita harus tahu bagaimana konsep serta fungsinya dalam praktek muamalah, kenapa transaksi dalam akad ini masih belum maksimal dan menjadi penopang dalam mamaksimalkan fungsi sosial lembaga keuangan di Indonesia ? sampai saat ini produk apa saja yang memaki akad qardh dalam industri perbankan syariah ?

\section{Pembahasan}

\section{Pengertian Qardh}

Menurut etimologi Qardh adalah bentuk masdar dari kata qaradha asy-syai'yaqridhuhu, yang artinya dia memutuskanya.

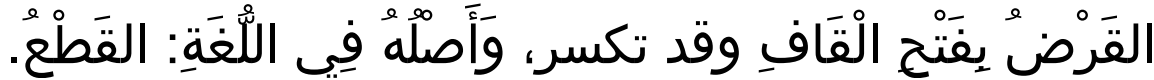

Qardh berarti memutus. Dikatakan qaradhtu asy-syai'a bil-miqradh, aku memutus sesuatu dengan gunting. Al-Qardh juga bisa diartikan sebagaipemilik dana memberikan pinjaman kepada seseorang untuk dibayar6.

${ }^{5}$ UU Nomor 21 Tahun 2008 tentang Perbankan Syariah, Pasal 2 berbunyi : Perbankan Syarian dalam melakukan kegiatan usahanya berasaskan prinsip syariah, demokrasi ekonomi, dan prinsip kehati-hatian. Pasal 3 berbunyi: Perbankan Syariah bertujuan menunjang pelaksanaan pembangunan nasional dalam rangka meningkatkan keadilan, kebersamaan, dan pemerataan kesejahteraan rakyat. Pasal 4 berbunyi: 1) Bank Syariah dan UUS wajib menjalankan fungsi menghimpun dan menyalurkan dana masyarakat; 2) Bank Syariah dan UUS dapat menjalankan fungsi sosial dalam bentuk lembaga baitul mal, yaitu menerima dana yang berasal dari zakat, infak, sedekah, hibah, atau dana sosial lainnya dan menyalurkannya kepada organisasi pengelola zakat; 3) Bank Syariah dan UUS dapat menghimpun dana sosial yang berasal dari wakaf uang dan menyalurkannya kepada pengelola wakaf (nazir) sesuai dengan kehendak pemberi wakaf (wakif), 4) Pelaksanaan fungsi sosial sebagaimana dimaksud pada ayat (2) dan (3) sesuai dengan ketentuan peraturan perundang-undangan

90 Studi Multidisipliner Volume 6 Edisi 12019 M/ 1440 H 
Adapun menurut terminologis akad qardh adalah memberikan pinjaman /harta kepada pihak lain yang akan memanfaatkannya dan mengembalikan pinjaman tersebut dikemudian hari.7Menurut Firdaus at al., qardh adalah harta yang diberikan kepada orang lain yang dapat ditagih atau diminta kembali, dikemudian hari sesuai kesepakatan. Dalam kajian atau literatur fikih, qardh diklasifikasikankepada aqad tathawwu'iatau akad saling tolong menolong dan bukan transaksi pengambilan untung (komersil) untuk pihak peminjam. ${ }^{8}$

Menurut ulama Hanafiyah:

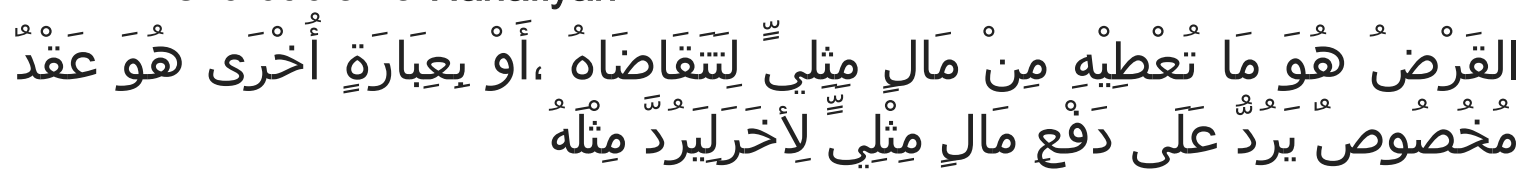

Artinya: "Qardh adalah harta yang diberikan seseorang dari harta mitsil (yang memiliki perumpamaan) untuk kemudian dibayar atau dikembalikan. Atau dengan ungkapan yang lain, qardh adalah suatu perjanjian yang khusus untuk menyerahkan harta (mal mitsil) kepada orang lain untuk kemudian dikembalikan persis seperti yang diterimanya."9

Sayyid Sabiq memberikan definisi qardh sebagai berikut:

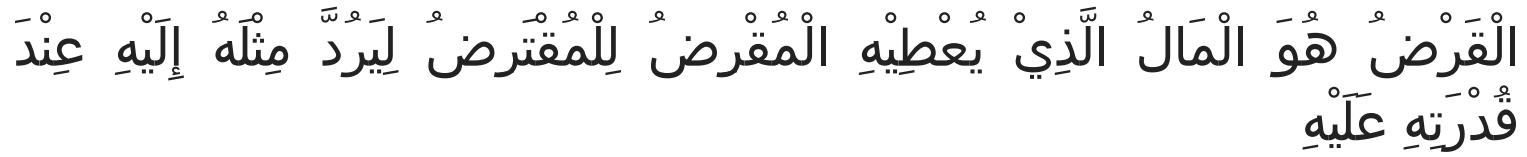

Artinya: "Al-qardh adalah harta yang diberikan oleh pemberi hutang (muqridh) kepada penerima utang (muqtaridh) untuk kemudian dikembalikan kepadanya (muqridh) seperti yang diterimanya, ketika ia telah mampu membayarnya."10

${ }^{6}$ Abdul Rahman Al-Jaziri, Al-Figh 'Ala Madzahibil Arba'ah Juz 2 (Libanon,Beirut: DarAlKutub Al-IImiyah, 2003), hlm. 303

${ }^{7}$ Abdullah bin Muhammad ath-Thayar, dkk. Ensiklopedi Fiqih Muamalah, terj. Miftahul Khair, Cet.1 (Yogyakarta: Maktabah al-Hanif, 2009), hlm. 153.

8Ismail Nawawi, Fikih Muamalah Klasik dan Kontemporer (Bogor: Ghalia Indonesia, 2012), hlm. 178.

9Ahmad Wardi Muslich, Fiqh Muamalah (Jakarta: Amzah, 2010), hlm. 273.

${ }^{10}$ Sayid sabiq, Fiqh As-Sunnah, Cet. 3, (Beirut: Dar Al-Fikr, 1977), juz 3, hlm 128 
Rukiah

Adapun pendapat Syafi'iyah adalah sebagai berikut:

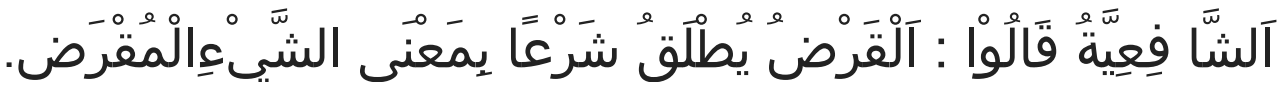

Artinya: "Syafi' iyah berpendapat bahwa qardh dalam istilah syara' diartikan dengan sesuatu yang diberikan kepada orang lain (yang pada suatu saat harus dikembalikan)."11

Akad atau Perjanjian qardh adalah perjanjian pinjam meminjam. Dalam kontrakqardh, pemberi pinjaman (kreditor) memberikan pinjaman kepada pihak lain dengan syarat penerima pinjaman akan mengembalikan pinjamantersebut pada waktu yang telah diperjanjikan dengan jumlah yang sama ketika pinjaman itu diberikan tanpa adanya tambahan apapaun. ${ }^{12}$

Dari definisi di atas dapat kita simpulkan sesungguhnya akad qardh merupakan salah satu jalan untuk ber-taqarrub kepada Allah Subahana huwata'ala dan merupakan aktivitas muamalah yang bercorak ta'awun (tolong menolong) dengan pihak lain untuk memenuhi kebutuhannya, karena muqtaridh (penghutang/debitur) tidak diwajibkan memberikan iwadh (tambahan) dalam pengembalian harta yang dipinjamnya itu kepada muqridh (yang memberikan pinjaman/kreditur), karena qardh menumbuhkan sifat kasih sayang terhadap manusia, memberikan solusi bagi kesusahan orang

Menurut fatwa, al-qardh ialah, "Akad pinjaman kepada nasabah dengan ketentuan bahwa nasabah wajib mengembalikan dana yang diterimanya kepada Lembaga Keuangan Syariah pada waktu yang telah disepakati oleh Lembaga

${ }^{11}$ Mushtafa Al-Babiy Al-Halabiy, Al-Muamalat al-maddiyah wa al-adabiyah (Mesir: Ali Fikri ,1356, hlm. 346.

${ }^{12}$ Sutan Remy Sjahdeini, Perbankan Islam dan Kedudukannya dalam Tata Hukum Perbankan Indonesia (Jakarta: Pustaka Umum Grafiti, 2007, hlm. 75

92 Studi Multidisipliner Volume 6 Edisi 12019 M/ 1440 H 
Keuangan Syariah dan nasabah."artinya kesepakatan itu tertulis didalam kontrak dan mengikat kedua belah pihak yang berkontrak ${ }^{13}$

hakikat kontrak al-qardh adalah pertolongan dan kasih sayang bagi yang meminjam. Transaksi ini bukan sarana mencari manfaat bagi yang meminjamkan,didalamnya tidak ada imbalan dan kelebihan pengembalian. Dia mengandung nilai kemanusiaan dan sosial yang penuh kasih sayang untuk memenuhi kebutuhan peminjam. Adanya pengembalian keuntungan oleh yang meminjamkan (muqtaridh) dana akan membatalkan kontrak al-qardh.

Dari beberapadefinisi Qardh yang dijelaskan di atas dapat disimpulkan bahwa qardh dilihatdari berbagai perspektif, mulai dari etimologi, terminologi sampai kepada hukum syara'nya adalah bertolak belakang dengan tujuanBank yang notabenenya bergerak dibidang jasa yang mustahil tidak menginginkan keuntungan.

Dalam hal ini Bank diperbolehkan mengenakan biaya administrasi, dengan berdasarkan pada Fatwa Dewan Syari'ah Nasional NO: 19/DSN-MUI/IV/2001 Tentang Al-Qardh yang memperbolehkan lembaga keuangan membebankan biaya administrasi kepada nasabah. Dengan ketentuan biaya administrasi tidak boleh berdasarkan perhitungan besarnya dana qardh yang diberikan.Landasasan Hukum Al-Qardh

Dasar Hukum Al-Qardh dalam Al-quran terdapat pada surah Al-Baqarah 2: (245) yang artinya:

Siapakah yang mau memberi pinjaman kepada Allah, pinjaman yang baik (menafkahkan hartanya di jalan Allah), Maka Allah akan meperlipat gandakan pembayaran kepadanya dengan lipat ganda yang banyak. dan Allah menyempitkan dan melapangkan (rezki) dan kepada-Nya-lah kamu dikembalikan ${ }^{14}$

\footnotetext{
${ }^{13}$ Atang Abd. Hakim, Fiqh Perbankan Syariah Transformasi Fiqh Muamalah ke dalam Peraturan Perundang-undangan (Bandung: PT. Refika Aditama, 2011), hlm. 267

${ }_{14}$ Al- Quran dan terjemahan - Al -bayan (Semarang : Cv. Asy syifa, 2011), hlm. 100
} 
Dan surah Al-Baqarah 2:(280) yang artinya:

Dan jika (orang yang berhutang itu) dalam kesukaran, Maka berilah tangguh sampai Dia berkelapangan. dan menyedekahkan (sebagian atau semua utang) itu, lebih baik bagimu, jika kamu mengetahuir.

Sedangkan landasan hukum dalam hadis

Qiradh merupakan salah satu bentuk taqarrub kepada Allah swt., karena qiradh berarti berlemah-lembut dan mengasihi sesama manusia, memberikan kemudahan dan solusi dari duka dan kesulitan yang menimpa orang lain. Islam menganjurkan dan menyukai orang yang meminjamkan (qiradh), dan membolehkan bagi orang yang diberikan qiradh, serta tidak menganggapnya sebagai sesuatu yang makruh, karena dia menerima harta untuk dimanfaatkan dalam upaya memenuhi kebutuhan hidupnya, dan peminjam tersebut mengembalikan harta seperti semula.Dasar hukum dari as-sunnahsebagai berikut:

Dari Ibnu Mas"ud, Rasulullah SAW bersabda:

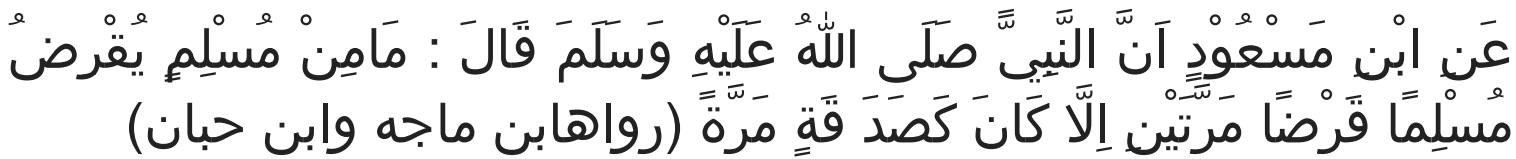

Artinya: "Dari Ibn Mas'ud bahwa Rasulullah SAW, bersabda, "tidak ada seorang muslim yang menukarkan kepada seorang muslim qarad dua kali, maka seperti sedekah sekali." (HR. Ibn Majah dan Ibn Hibban) ${ }^{16}$

\section{Rukun Utang-Piutang (al-Qardh)}

Adapun yang menjadi rukun qardh ada tiga, yaitu:

a. Shighat Qardh

Shighat terdiri dari ijab dan qabul. Redaksi ijab contohnya, "Aku meminjamimu," "Aku mengutangimu," "Ambilah barang ini dan nanti ganti

${ }^{15} \mathrm{Al}$ - Quran dan terjemahan - Al -bayan hlm. 120

${ }^{16}$ Wahbah Az-zuhaili, Al-Fiqhul Islami wa Adillatuhu. Jilid 4 hlm. 720.

94 Studi Multidisipliner Volume 6 Edisi 12019 M/ 1440 H 
dengan barang yang sejenis," atau "Aku berikan barang ini kepadamu dengan syarat kamu mengembalikan gantinya." Menurut pendapat yang sah, disyaratkan ada pernyataan resmi tentang serah terima pinjaman.

Redaksi qabul seharusnyasesuai dengan isi ijab, seperti jual beli. misalnya pemberi pinjaman berkata, "Aku memberimu hutang 700 dirham," lalu peminjam menerima 500 dirham, atau sebaliknya, maka akad tersebut tidak sah.

Sebagian ulama Syafi"iyah berpandangan bahwa jika peminjam berkata kepada pemberi pinjaman, "Berikanlah saya utang sekian," lalu dia meminjamnya; atau peminjam mengirim seorang utusan kepada pemberi pinjaman, lalu dia mengirim sejumlah harta kepadanya, maka akad qardh tersebut sah. Menurut al-Adzra"i, sistem tersebut dilakukan menurut ijma' ulama.

b. Para Pihak yang Terlibat Qardh

Pemberi pinjaman (muqridh) harus cakap dalam arti mendermakan harta, sebab akad qardh mengandung unsur kesunahan. Di sisi lain disyaratkan peminjam (muqtaridh) harus cakap bermuamalah. Jadi hanya pihak yang cakap secara hukum yang boleh bertransaksi dengan akad Qardh seperti halnya jual beli.

c. Barang yang Dipinjamkan

Objek qardh harus bisa diserahterimakan dan dapat dijadikan barang pesanan (muslam fih), yaitu berupa barang yang mempunyai nilai ekonomis (boleh dimanfaatkan menurut syara) dan ciri - cirinya harus diketahui karena ia layak sebagai pesanan. Bisa terukur dan mudah diperoleh serta dibatasi dengan karakter tertentu.

ObjekQardh juga hanya bisa dilakukan pada harta yang telah diketahui kadarnya. Apabila seseorang mengutangkan makanan yang tidak diketahui takarannya, itu tidak boleh, karena qardh menuntut pengembalian barang 
yang sepadan. Jika kadar barang tidak diketahui, tentu tidak mungkin melunasinya. ${ }^{17}$

\section{Harta yang Dikembalikan}

Ulama bersepakat bahwa peminjam wajib mengembalikan harta misalnya meminjam harta mitsli, maka harus dikembalikan dengan harta mitsil ataupun sejenisnya. Menurut pandangan ulama selain Hanafiyah bila pinjaman berupa misalnya harta qimiy yaitu meminjam domba akan tetapi dikembalikan dengan kambing yang ciri-cirinya harus mirip dengan domba yang menjadi objek pinjaman atau juga misalnya.

\section{Waktu Pengembalian}

Ada perbedaan pendapat diantar ulama mengenai pengembalian harta yang dipinjam, menurut ulama Malikiyah, pengembalian harta yang dipinjam harus dikembalikan sesuai dengan kesepakatan diawal, atau terikatwaktu. Sementara menurut ulama selain ulama malikiyah harta yang dipinjam tidak dibatasi oleh waktu kapan saja boleh dikembalikan, Karena qardh adalah akad yg tidak mengenal batas waktu. ${ }^{18}$

\section{Tambahan dalam Utang-Piutang (al-Qardh)}

Ada dua macam penambahan pada qardh (utang-piutang), yaitu sebagaimana berikut ini:

a. Tambahan yang disyaratkan diawal perjanjian,tambahan ini telah dilarang berdasarkan ijma ulama, menambah kadar atau ukuran harta yang dipinjam. Tambahan atau manfaat lain yang diperoleh dari utang yang diisyaratkan misalnya, seperti perkataan: "Aku memberi utang kepadamu

\footnotetext{
${ }^{17}$ Wahbah Zuhaili, Fiqh Imam Syafi'l(Jakarta: Almahira, 2010), Cet. 1, hlm. 20-21
}

${ }^{18}$ Wahbah az-Zuhaili, Fiqih Islam 5 (Jakarta: Gema Insani, 2011), hlm. 378-379.

96 Studi Multidisipliner Volume 6 Edisi 12019 M/ 1440 H 
dengan syarat kamu memberi hak kepadaku untuk menempati rumahmu," atau syarat manfaat lainnya, yang menyiratkan adanya rekayasa riba.

b. Tambahann terhadap pembayaran utang boleh dilakukan apabila tidak menjadi syarat diawal perjanjian. maka maka tambahan ini boleh dan termasuk pembayaran yang baik berdasarkan hadits yang telah dikemukakan di pasal dasar al-qardh (utang-piutang). ${ }^{19}$ Pengembalian harta yang dipinjam diwajibkan seimbang kadar dan ukurannya. Agar terhindar dari potensi riba. Dengan demikian, pengembalian barang pinjaman, baik yang berpotensi riba ataupun bukan, kadarnya harus sama, tidak boleh lebih sedikit atau lebih banyak, juga tidak boleh lebih berkualitas atau lebih jelek. Demikianlah hukum dasarnya. Jikayang berhutang atas keinginannya sendiri melebihkan atau menambah jumlah pembayaran itu boleh diterima dan merupakan kebaikan bagi yang berhutang 20

\section{Sumber Dana Qardhdan Kendala pelaksanaan di LKS}

Pembiayaan qardh secara finansial sebenarnya tidak memberikan dampak kepada bank syariah. Ada dua sumber pembiayaan Qardh di bank syariah yaitu sumberdari dalam Bank (intern) dan luar Bank (ekstren) sebagaiberikut:

a. Qardh yang diperuntukkan untuk tujuan membantu keuangan Jangka pendek dan prosesnya cepat. Talangan dana ini dapat diperoleh dari modal bank atau equitas (sumber Intern)

b. Qardh yang diperuntukkan untuktujuan membantu UKM atau kegiatan sosial dana ini dapat bersumber dari dana Ziswaf, Di samping itu dana ini bisa juga

\footnotetext{
${ }_{19}$ Abdullah bin Muhammad Ath-Thayyar, Abdullah bin Muhammad Al-Muthlaq dan Muhammad bin Ibrahim, Ensiklopedi Fiqih Muamalah dalam Pandangan Madzhab (Yogyakarta: Maktabah Al-Hanif, 2009), hlm. 168-169

${ }^{20}$ R. Abdul Djamali, Hukum Islam Berdasarkan Ketentuan Kurikulum Konsorsium IImu Hukum (Bandung: CV. Mandar Maju,1997), hlm. 165
} 
diperoleh dari pendapatan-pendapatan yang diragukan seperti jasa nostro di bank, koresponden dari bank - bank konvensional, bunga jaminan Letter of Credit (L/C) di bank asing, dan sebagainya. ${ }^{21}$

Apabila nasabah mengalami kendala untuk mengembalikan hutangnya selurunya atau sebagian, bank dan nasabah bisa memberikan keringanan, berupa perpanjangan jangka waktu hutang. Dan jika nasabah juga tidak mampu lagi dan usaha dalam keadaan pailit, bank bisa mengapuskan hutangnya.

Akan tetapi pembebasan hutang ini jarang terjadi karena bank atau LKS lainnya tidak bisa lepas dari tujuan bisnis (komersialisasi) apalagi hal ini dijamin oleh Fatwa DSN MUI, pada pasal pertama ayat (4) disebutkan bahwa "LKS dapat meminta jaminan kepada nasabah bilamana dipandang perlu"22. Aplikasi qardh dalam lembaga keuangan syariah diperlakukan sama dengan pembiayaan lainnya untuk menilai kelayakan nasabah yang akan menerima pinjaman qardh, yaitu dengan prinsip 5C atau lebih dikenal Five C's of Credit yaitu (Character, Capacity, Capital, Collateral Condition.) atau juga Prinsip $5 \mathrm{C}$ ini bisa ditambah dengan $2 \mathrm{C}$,yakni (Coverage of insurance dan Contraint) Serta penilaian dengan prinsip 5 P dalam kredit atau five P's of Credit yakni Person atau People, Purpose, Prospect, Payment dan Protection. Walaupun menurut ketentuan bank dan menurut prinsip Akad pembiayaan qardh adalah pinjaman yang wajib dikembalikan sebesar pokok pinjaman dan akan digulirkan lagi kepada nasabah yang lain. Tapi kenyataan yang ada dalam persepsi nasabah masih menganggap pembiayaan Qardh sama dengan bantuan pemerintah. Pemahaman kepada masyarakat bahwa pinjaman qardh merupakan hutang yang wajib dikembalikan

\footnotetext{
${ }^{21}$ Nur Haida, Mengukur Fungsi Sosial dalam Perkembangan Produk Qardhul Hasan Pada Perbankan Syariah di Indonesia, Jurnal Al Amwal (Jurnal Ekonomi dan Perbankan vol. 7 no 2 2016), hlm, 201

${ }^{22}$ Fatwa DSN MUI No. 19/DSN-MUI/IV/2001 tentang al-qardh
} 
menjadi tugas pokok bank Syariah agar penyalurkan pinjaman qardh sesuai maksud dan tujuan serta berjalan profesional. ${ }^{23}$

\section{Aplikasi $A /$ - Qardh di Lembaga Keuangan Syariah}

Apliaksi Qardhdalam perbankanadalah merupakan pinjaman uang. Pinjaman qardh diberikan oleh bank kepada nasabahnya sebagai fasilitas talangan bagi nasabah yang mengalami overdraft. Fasilitas ini biasanya satu paket dengan pembiayaan lain, tujuanya untuk memudahkan nasabah bertransaksi. Aplikasi qardh dalam perbankan biasanya dalam empat hal:

1. Pembiayaan talangan haji, dimana nasabah calon haji diberikan pinjaman talangan untuk memenuhi syarat penyetoran biaya perjalanan haji. Nasabah akan melunasinya sebelum keberangkatan haji. Dalam aplikasi talangan haji terdapat akad gardh wal ijarah produk ini ditawarkan oleh Bank syariah Mandiri.

Salah satu Bank yang telah menyediakan sarana talangan haji ini adalah Bank Syari'ah Mandiri sebagai jalan untuk membantu nasabah dalam perencanaan pelaksanaan ibadah hajinya. Produk pembiayaan ini bertujuan untuk mempermudah menunaikan ibadah haji yaitu dengan membiayai dana talangan haji. Produk dana talangan haji adalah menggunakan akad qardh wal ijarah dengan cara ini calon haji akan lebih muda memperoleh nomor porsi haji. Ketentuan tentang pembiayaan pengurusan haji lembaga keuangan syariah diatur dengan fatwa DSN-MUI Nomor: 29/DSN-MUI/VI/200224.

Akad qardh diterapkan pada pinjaman nasabah berupa talangan haji sebesar Rp. 22.500.000. hingga mendapatkan porsi haji. Sedangkan

\footnotetext{
${ }^{23}$ Muhammad Akhyar Adnan, Evaluasi Non Performing Loan (NPL) pinjaman qardhul hasan (studi kasus di bni syariah Cabang Yogyakarta) JAAI volume 10 NO. 2, desember 2006, hlm. 169.

${ }^{24}$ DSN-MUI, Himpunan Fatwa DSN-MUI (Jakarta: Gaung Persada, 2006), hlm. 171.
} 
akad ijarah digunakan untuk menyewa sistem SISKOHAT(Sistem Komputerisasi Haji Terpadu) adalah sistem yang tersambung (on line) dengan Bank Penerima Setoran ONH, 27 Kanwil Departemen Agama Propinsi, 6 Daerah Embarkasi dan Arab Saudi sebagai upaya meningkatkan pelayanan penyelenggaraan haji secara menyeluruh dan terpadu sejak masa pendaftaran, penyelesaian administrasi dokumen serta pada operasional di Embarkasi dan Arab Saudi.

Kelebihan dari sistem SISKOHAT antara lain dapat memberikan kepastian kepada calon haji dan mampu mencegah terjadinya "overquota" Di samping itu, SISKOHAT mampu memberikan informasi dengan cepat, tepat dan akurat, baik untuk kepentingan manajemen, jamaah haji maupun masyarakat umum lainnya. ${ }^{25}$

2. Pinjaman tunai (cash advanced) dari produk kartu kredit syariah, di mana nasabah diberi keleluasaan untuk menarik uang tunai milik Bank melalui ATM. Nasabah akan mengembalikan berdasarkan jangka waktu yang ditentuan.

Setidaknya terdapat 3 (tiga) jenis akad dalam kartu kredit syariah, yakni :

a. kafalah (Penjamin Transaksi)

Dalam akad kafalah, bank sebagai penerbit kartu bertindak sebagai penjamin (kafi) bagi pemegang kartu terhadap merchant atas semua kewajiban bayar (dayn) yang timbul dari transaksi antara pemegang kartu dengan merchant, dan atau penarikan tunai selain bank atau ATM bank Penerbit Kartu, dengan demikan dapat dikatakan bahwa merchant bertindak sebagai pihak penerima jaminan dari bank berdasar prinsip kafalah. Atas pemberian kafalah ini, penerbit kartu dapat menerima fee ( $u j r a h)$ dari pemegang kartu.

\footnotetext{
${ }^{25}$ Departemen Agama RI, Bunga Rampai Perhajian (Jakarta: Depag RI, 1998), hlm. 2223.
}

100 Studi Multidisipliner Volume 6 Edisi 12019 M/ $1440 \mathrm{H}$ 
b. Qardh

Qardh adalah pemberian pinjaman untuk pengambilan tunai dalam akad qardh bank sebagai penerbit kartu bertindak selaku pemberi pinjaman (muqridh) kepada pemegang kartu (muqtaridh) melalui penarikan tunai dari bank atau ATM bank penerbit kartu.

c. ljarah

ljarah adalah biaya keanggotaan (iuran tahunan). Dalam akad ijarah ini penerbit kartu adalah penyedia jasa sistem pembayaran dan pelayanan terhadap pemegang kartu. Pemegangkartu dikenakan membership fee. Semua fee yang ditetapkan pada kartu kredit syariah harus dinyatakan jumlahnya pada saat akad aplikasi kartu secara jelas dan nilainya tetap, kecuali untuk merchant fee.

1. Sebagai pinjaman kepada UKM (usaha Kecil Menengah), karena kalau bank menawarkan pembiayaan lain seperti skema jual-beli, ljarah atau bagi hasil yang sifatnya komersil akan memberatkan nasabah. Aplikasi ini sesuai dengan prinsip qard pinjaman murni ( qardul hasan) kepada pengusaha kecil,karena memiliki prinsip tolong menolong.

2. Sebagai pinjaman kepada pengurus Bank, karyawan dan lain-lain. Bank menyediakan fasilitas ini untuk memastikan terpenuhinya kebutuhan karyawan Bank. Karyawan atau pengurus Bank akan mengembalikannya secara cicilan melalui pemotongan gajinya dan upaya ini sebagai salah satu peran fungsi motivasi kepada karyawan terhadap bank untuk meningkatkan loyalitas karyawan.

\section{Penutup}

1. Perjanjian qardh adalah perjanjian pinjaman. Dalam perjanjian qardh, pemberi pinjaman (kreditor) memberikan pinjaman kepada pihak lain dengan ketentuan penerima pinjaman akan mengembalikan pinjaman 
tersebut pada waktu yang telah diisyaratkan dengan jumlah yang sama ketika pinjaman itu diberikan

2. Landasan hukum Al-Qardh adalah:

a. Al quran surah Al- Baqrah ayat 245 dan 280

b. "Dari Ibn Mas'ud bahwa Rasulullah SAW, bersabda, "tidak ada seorang muslim yang menukarkan kepada seorang muslim qarad dua kali, maka seperti sedekah sekali." (HR. Ibn Majah dan Ibn Hibban)

c. Masih banyaknya kendala dilapangan berkaitan dengan mekanisme dan itikad baik nasabah dalam mengembalikan pinjaman dan belum maksimalnya lembaga keuangan dalam meningkatkan penyaluran dana qardh

d. Aplikasiqardh dalam perbankan syariah berupa:

1. Talangan haji

2. Kartu kredit syariah

3. Pinjaman untuk UKM (usaha Kecil Menengah0

4. Pinjaman untuk pegawai bank atau lembaga kauangan yang bersangkutan

\section{Daftar Pustaka}

Ahmad WardiMuslich, Fiqh Muamalah, Jakarta: Amzah, 2010.

Al- Quran dan terjemahan (Al -bayan), Semarang : Cv. Asy syifa, 2001.

102 Studi Multidisipliner Volume 6 Edisi 12019 M/ 1440 H 
Atang,Abd. Hakim, Fiqh Perbankan Syariah Transformasi Fiqh Muamalah ke dalam Peraturan Perundang-undangan, Bandung: PT. Refika Aditama, 2011

Departemen Agama RI, Bunga Rampai Perhajian, Jakarta: Depag RI, 2011.

DSN-MUI, Himpunan Fatwa DSN-MUI2006, Jakarta: Gaung Persada.

Fatwa DSN MUI No. 19/DSN-MUI/IV/2001 tentang al-qardh.

Halabiy, Mushtafa Al-Babiy Al-Muamalat al-maddiyah wa al-adabiyah, terj. Ali Fikri, mesir 1356.

IsmailNawawi, Fikih Muamalah Klasik dan Kontemporer, Bogor: Ghalia Indonesia, 2012.

Jaziri, Abdul Rahman, Al-Fiqh 'Ala Madzahibil Arba'ah Juz 2, Libanon, Beirut: Dar- AlKutub Al-IImiyah, 2003.

Muhammad, Akhyar Adnan, Evaluasi Non Performing Loan (NPL) Pinjaman Qardhul Hasan (studi kasus di BNI Syariah Cabang, Yogyakarta, JAAI volume 10 NO. 2, Desember 2006.

Nur Haida, Mengukur Fungsi Sosial dalam Perkembangan Produk Qardhul Hasan Pada Perbankan Syariah di Indonesia, Jurnal Al Amwal (Jurnal Ekonomi dan Perbankan vol. 7 no 2, 2016.

R. Abdul Djamali, 1997, Hukum Islam Berdasarkan Ketentuan Kurikulum Konsorsium IImu Hukum, Bandung: CV. Mandar Maju.

Sabiq, Sayid, Fiqh As-Sunnah, Cet. 3, Beirut: Dar Al-Fikr, 1977.

Sutan RemySjahdeini, Perbankan Islam dan Kedudukannya dalam Tata Hukum Perbankan Indonesia, Pustaka Umum Grafiti, Jakarta, 2007.

Thayar, Abdullah bin Muhammaddkk, Ensiklopedi Fiqih Muamalah, terj. Miftahul Khair, Cet. 1; Yogyakarta: Maktabah al-Hanif, 2009.

Zuhaili, Wahbah, Al-Fighul Islami wa Adillatuhu, terj. Abdul Hayyie al- Kattani, dkk, cet: 1. Jakarta: Gema Insani, jilid 5, 2011.

Zuhaili, Wahbah, Fiqh Imam Syafi'i, Jakarta: Almahira, Cet. 1, 2010.

Zuhaili, Wahbah, Fiqih Islam 5, Jakarta: Gema Insani, 2011. 